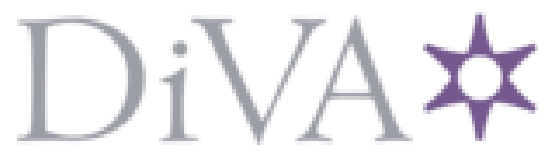

http://www.diva-portal.org

This is the published version of a paper published in Analysis.

Citation for the original published paper (version of record):

Hattiangadi, A. (2016)

The Rules of Thought By Jonathan Jenkins Ichikawa and Benjamin W. Jarvis.

Analysis, 76(3): 393-397

https://doi.org/10.1093/analys/anw042

Access to the published version may require subscription.

N.B. When citing this work, cite the original published paper.

Permanent link to this version:

http://urn.kb.se/resolve?urn=urn:nbn:se:su:diva-139781 
inevitable that partisan readers will object that other themes, and other literatures, have been unjustly neglected. However, it is precisely the strength of these short and focused books that they each, in their own way, hit the nail on the head, and so provide an opportunity for others to 'come and do it better', as Wittgenstein put it in the preface to the Tractatus.

\author{
DAVID G. STERN \\ 276 EPB, University of Iowa \\ Iowa City, IA 52242-1408, USA \\ david-stern@uiowa.edu
}

\title{
References
}

Fogelin, R. 2009. Taking Wittgenstein at his Word. Princeton: Princeton University Press. Merrill, H. and Jaakko, H. 1986. Investigating Wittgenstein. Oxford: Blackwell.

Kripke, S. 1982. Wittgenstein on Rules and Private Language. Cambridge: Harvard University Press.

Ricketts, T. 1986. Frege, the Tractatus, and the Logocentric Predicament. Nô̂s 19: 3-15. Wittgenstein, L. 1923. Tractatus Logico-Philosophicus. London: Routledge and Kegan Paul.

\section{The Rules of Thought}

\author{
By Jonathan Jenkins Ichikawa and Benjamin W. Jarvis \\ Oxford University Press, 2013. xii +354 pp. $£ 35.00$
}

The Rules of Thought, by Jonathan Jenkins Ichikawa and Benjamin Jarvis (henceforth IJ), is a dense and ambitious book whose principal aim is to defend the view that philosophical inquiry is a priori inquiry into essential natures. The book covers a broad range of philosophical issues spanning the philosophy of mind and language, the epistemology of metaphysical modality and the philosophy of philosophy. It will be of considerable interest to many, since there is something in it for just about everyone. That said, the authors do not do as much as one might like to make their views accessible to the uninitiated or convincing to the unconverted.

The book is divided into three parts: the first presents a theory of what pure rational thinking consists in; the second defends the modal rationalist thesis that we can know about metaphysical modalities a priori; the third consists of a critique of the view that intuitions play a distinctive role in philosophical knowledge. Due to space limitations, I will confine my remarks to the first two parts.

1. What does pure rational thinking consist in? According to IJ, it consists in following rules of thought derived from the conclusive rational relations between propositions. For IJ, propositions are structures of concepts, where concepts are abstract objects, distinct from cognitive states or symbols in the language of thought. Propositions and concepts have Fregean senses, where Fregean senses are identified 
with systems of conclusive rational relations. Moreover, propositions are hyperintensional, much like sentences, individuated both by their syntax and the conclusive rational relations in which they stand. For example, IJ say that the proposition $<J o e$ is a mailman $>$ and $<$ All mailmen are industrious $>$ are rationally conclusive for $<$ Joe is industrious $>$ (29). These conclusive rational relations are essential to propositions - what it is to be the proposition that $<$ Joe is a mailman $>$ is to stand in a certain system of rational relations (Ch. 1).

If rational thinking consists in rule following, what is it for an arbitrary subject $S$ to follow a rule? The morass of issues surrounding this question are well known from Kripke's (1982) influential discussion of Wittgenstein's rule following considerations. Kripke asks what makes it the case that $S$ follows the rule for addition rather than quaddition, where $x$ quus $y=x$ plus $y$, if $x, y \leq n$ and $x$ quus $y=5$, otherwise. In Kripke's example, $n=57$, but let's say that $n$ is a very large number (i.e. one that is represented by a numeral $\geq 10 \mathrm{~km}$ long). Kripke argues that the fact that $S$ follows the plus-rule is neither constituted by (a) any intentional facts, because that way lies regress, nor by (b) $S$ 's dispositions or any other non-intentional facts, because the non-intentional facts are compatible with the hypothesis that $S$ follows the quus-rule. IJ reject (a) on Kripkean grounds, and they defend a version of (b), though they summarily dismiss Kripke's arguments against (b), along with the arguments of those of us who have questioned implicit rule following and the normativity of intentionality (Cf. Glüer 1999; Glüer and Wikforss 2009; Hattiangadi 2006, 2007; Papineau 1999). IJ do not address our arguments at any length; they simply state that they see no non-question-begging reasons to think that there cannot be implicit rule-following $(41, \mathrm{fn} ., 62)$, and that opposition to the normativity of intentionality is not well motivated (39). At the same time, they fail to give an adequate account of what implicit rule following consists in.

IJ claim that $S$ 's following a rule involves a disposition to approximately adhere to it. But this cannot be what following the plus-rule consists in. Suppose that $S$ typically gives the sum of two numbers $\leq n$ when asked, while in response to sums involving numbers $>n$, she faints before she can give an answer. $S$ 's disposition approximately adheres to both the plus-rule and the quus-rule. So, her disposition to approximately adhere to the plus-rule does not determine which rule she follows.

IJ further appeal to the proper systematization of dispositions, which is constrained by explanatory power (82), resistance to revision (82), relevance for practical pursuits (83) and consilience with the community (116). However, S's properly systematized dispositions are also compatible with the quus hypothesis. First, the quus hypothesis explains why $S$ gives the answers that she does just as well as the plus hypothesis. Second, if $S$ faints when asked to add numbers $>n$, she will faint when asked to revise her answers, so her dispositions are resistant to revision in light of both rules. Third, both rules are equally relevant to her practical pursuits, insofar as any depend on her adding numbers $\leq n$, and neither are relevant to any practical pursuits that depend on her adding numbers $>n$. Fourth, assuming that $n$ is so large that everyone in the linguistic community would faint if asked to add numbers $>n$, consilience with the linguistic community will not determine which rule $S$ follows. So $S$ 's properly systematized dispositions do not constitute her following the plus-rule.

IJ suggest in some places that $S$ 's following a rule $R$ involves $S$ being in some cognitive state $M$ whose functional role is to adhere to $R$ (39). Perhaps if $S$ is in $M$ and $M$ has the functional role of adhering to the plus-rule ( $M$ has the plus-role), then 
$M$ means addition. But what makes it the case that $M$ has the plus-role, rather than the quus-role? IJ suggest that this has to do with which role best serves $S$ 's interests $(7,40)$. But as we have just noted, $S$ 's interests are equally well-served if $M$ has the plus-role as if $M$ has the quus-role, since in both cases, her interests are equally wellserved when they depend on sums involving numbers $\leq n$, and equally badly served when they involve numbers $>n$. So, $S$ 's interests do not determine the functional role of $M$, and hence do not determine which rule $S$ follows.

IJ acknowledge that there is more to be said about rule following than they are able to say (41). Perhaps their aim was merely to give a partial account of rational thinking as rule following. But they do not explain why a partial account is sufficient for their purposes, and they do not address well-known objections. As a consequence, their positive account of rule following is unconvincing, as is their account of what rational thinking consists in.

2. IJ's views closely resemble the well-known views of Chalmers and Jackson (hereafter CJ) in crucial respects: both IJ and CJ endorse a Fregean theory of meaning and content and a rationalist account of modal epistemology (cf. Chalmers 2006, 2002; Chalmers and Jackson 2002; Jackson 1998). Given the similarities, it would have been good to get a better sense of how IJ propose to improve upon CJ's views. But IJ only attempt to explain how their view differs from CJ's (69).

IJ acknowledge the similarity between their notion of rational possibility or 'r-possibility' and Chalmers's notion of epistemic possibility (58). For IJ, an r-possible scenario is one that is represented by a class of hyperintensional propositions that does not jointly entail a rational absurdity (54). For Chalmers, an epistemically possible scenario is a maximal set of sentences that cannot be ruled out a priori (Chalmers 2002). However, IJ claim that their view differs from Chalmers's in one crucial respect: Chalmers accepts, while they deny, that every epistemic possibility corresponds to some metaphysical possibility. According to Chalmers, the epistemic possibility that water is not $\mathrm{H}_{2} \mathrm{O}$ corresponds to some metaphysically possible world such as Twin Earth, where the watery stuff is constituted by XYZ. When we consider Twin Earth as actual, that is, when we suppose that the Twin Earth scenario is an accurate description of our world, 'water is $\mathrm{H}_{2} \mathrm{O}$ ' comes out false, whereas if we consider the Twin Earth world as counterfactual, that is, when we suppose that the Twin Earth scenario describes a non-actual, metaphysically possible world, then 'water is $\mathrm{H}_{2} \mathrm{O}$ ' comes out true (Chalmers 2002, 2006: 61).

Yet it is unclear how significant this difference is. IJ claim to oppose Chalmers when they say that 'in virtue of being metaphysically possible, $w$ [=Twin Earth] is a possibility in which there is no water whatsoever no matter how one considers it (68)'. However, they appear to have misunderstood Chalmers, for they go on to explain that 'one can imaginatively represent in a coherent way ... the actual world to be a metaphysical possibility where the stuff with water's surface properties is uniformly composed of XYZ (69)' (see also 242-43). But this is in effect what Chalmers says. If IJ's view departs from Chalmers's view on this point, the departure appears to be insignificant.

Moreover, it is unclear whether IJ's defence of modal rationalism improves on CJ's. Indeed, IJ's Moderate Modal Rationalism (MMR) does not seem to be true as stated (245):

$$
\operatorname{MMR}: \diamond_{M}(<p>) \equiv\left(\diamond_{R}(<p>) \quad \& \sim \exists(<q>)\left[\sim \mathrm{A}(<q>) \quad \& \square_{R}(p \supset \mathrm{A}(<q>))\right]\right.
$$


IJ gloss MMR as saying that the proposition $<p>$ is metaphysically possible iff $<p>$ is r-possible and there is no proposition $<q>$ such that $<p>$ r-entails that the actual world is such that $\langle q\rangle$ when the actual world is not such that $\langle q\rangle$. $\langle p\rangle$ is r-possible iff there is some r-possible scenario at which it is true, and $\langle p\rangle$ r-entails $\langle q\rangle$ iff there is no r-possible scenario at which $\langle p\rangle$ is true and $\langle q\rangle$ is false.

However, there are counter-examples to MMR. Let $<p>$ be the proposition that the actual Aristotle lived in Peru. $\langle p>$ is metaphysically possible, since when $<p>$ is evaluated at metaphysically possible worlds, the actual Aristotle picks out Aristotle, and there is a possible world at which Aristotle lived in Peru. So the left side of MMR is true. However, the right side of MMR is false. Although $\langle p\rangle$ is r-possible, since there is a coherent scenario at which it is true, there is a proposition that is false at the actual world and which is r-entailed by $\langle p\rangle$ : that proposition is $\langle p\rangle$ itself. That is, since Aristotle did not live in Peru, $\sim \mathrm{A}(<p>)$ is true. At the same time, $\square_{R}(p \supset \mathrm{A}$ $(<p>))$ is true. To see why, recall that r-entailments hold between IJ's hyperintensional propositions, so that $\square_{R}(p \supset \mathrm{A}(<p>))$ is true iff there are no r-possible scenarios at which $\langle p>$ is true and $<\mathrm{A}(\langle p>)>$ is false. That is, to investigate whether $\square_{R}(p \supset \mathrm{A}(<p>))$ is true, we have to consider whether there is a rationally coherent scenario at which the actual Aristotle lived in Peru is true while the actual world is such that the actual Aristotle lived in Peru is false. And when we evaluate these propositions at scenarios, the actual Aristotle picks out the Aristotle of the scenario and the actual world picks out the world of the scenario. Given this, it is clear that there is no r-possible scenario at which $<p>$ is true and $<\mathrm{A}(<\mathrm{p}>)>$ is false. Thus $\square_{R}(p \supset \mathrm{A}(<p>))$ is true, and the left to right direction of MMR fails.

\author{
ANANDi HatTiangadi \\ Stockholm University \\ Swedish Collegium of Advanced Studies \\ anandi.hattiangadi@philosophy.su.se
}

\title{
References
}

Chalmers, D. 2002. Does conceivability entail possibility? In Conceivability and Possibility, eds. T.S. Gendler and J. Hawthorne, 145-200. Oxford: Oxford University Press.

Chalmers, D. 2006. The foundations of two-dimensional semantics. In Two-Dimensional Semantics, eds. M. García-Carpintero and J. Macià, 55-140. Oxford: Oxford University Press.

Chalmers, D. and Jackson, F. 2002. Conceptual analysis and reductive explanation. Philosophical Review 110: 315-61.

Ichikawa, J.J. and Jarvis, B.W. 2013. The Rules of Thought. Oxford: Oxford University Press.

Glüer, K. 1999. Sense and prescriptivity. Acta Analytica 14: 111-28.

Glüer, K. and Wikforss, A. 2009. Against content normativity. Mind 118: 31-70.

Hattiangadi. A. 2006. Is meaning normative? Mind and Language 21: 220-40. 
Hattiangadi. A. 2007. Oughts and Thoughts. Rule-Following and the Normativity of Content. Oxford: Oxford University Press.

Jackson. F. 1998. From Metaphysics to Ethics: A Defence of Conceptual Analysis. Oxford: Oxford University Press.

Kripke. S. 1982. Wittgenstein on Rules and Private Language. Cambridge, MA: Harvard University Press.

Papineau. D. 1999. Normativity and judgment. Aristotelian Society Supplementary Volume 73: 16-43.

\title{
A Naturalistic Epistemology: Selected Papers
}

\author{
By Hilary Kornblith, \\ Oxford University Press, 2015. $x+222$ pp. $£ 37.50$
}

This volume will be a most welcome addition to the personal library of anyone interested in contemporary epistemology: the papers here collected provide a very comprehensive and clear defence of one of the most radical and widely discussed research programs, as offered by one of its fiercest and lucid advocates. Kornblith's naturalistic epistemology is discussed from a number of perspectives touching on an extensive range of topics, including what epistemology is about, the importance of its social dimension, the link between epistemology and metaphysics, epistemic normativity, the critique of internalism, the extent to which externalist theories offer satisfactory explanations, the relation between human knowledge and animal knowledge, the reliance on intuitions in philosophical methodology and the broad theory of rationality. There is no doubt that the hope that 'collecting [the papers] in one place will serve to illuminate their interconnections and highlight the integrity of the vision that informs them' (1) has been fulfilled.

One way to describe Kornblith's naturalism is by contrasting it with rival approaches to epistemology. According to a popular reconstruction (Goldman and Pust 1998), epistemology engages in at least two substantial tasks: the descriptive one of identifying the properties that make a belief a case of knowledge, and the normative one of formulating norms to guide agents' epistemic activity so that they can acquire knowledge. For traditional analytic epistemology, both tasks can be achieved through the armchair method of advancing conceptual analyses and principles, and revising them in the light of counterexamples - all in splendid ignorance of the results of empirical research, as the saying goes. On the other hand, a brand of naturalism that we might dub moderate agrees with the traditional view that the descriptive task can be achieved from the armchair, but it insists that the normative part requires the identification of methods of belief-formation that are actually reliable, and thus it needs the contribution of empirical investigations: whether a method is reliable or not is an empirical question. By contrast, according to the kind of naturalism defended by Kornblith, which we may call uncompromising, traditional philosophical methods should play no role in epistemology; rather, we should appeal to the results of empirical investigation from the initial task of figuring out what knowledge is. 